\title{
Winter Biology of Culex pipiens quinquefasciatus Say, (Diptera: Culicidae) from Córdoba, Argentina
}

\author{
Walter R Almirón+, Mireya E Brewer
}

\author{
Centro de Investigaciones Entomológicas de Córdoba, Facultad de Ciencias Exactas, Físicas y Naturales, \\ Universidad Nacional de Córdoba, Av. V. Sarsfield 299 (5000) Córdoba, Argentina
}

\begin{abstract}
Adult cohorts and immature stages were kept under field conditions during the autumn and winter of three consecutive years. Survival, oviposition and development time from egg to adult were considered. The adult cohorts were studied under three experimental conditions: unfed cohorts, cohorts fed with sugar solution and cohorts fed with both sugar solution and blood (chicken). Female longevity showed significant differences among the three treatments. Females of unfed cohorts lived up to three weeks; females fed with sugar solution survived until six weeks, while those fed both with sugar and blood lived at most fourteen weeks; after the blood intake eggs were laid. In the immature stages, the highest relative mortality rates occurred during the egg and larval stages. Total pre-adult mortality varied between 59.09 and $89.71 \%$. The developmental duration from egg to adult was between 43-62 days; there were no differences among results obtained for the three years.
\end{abstract}

Key words: Culex pipiens quinquefasciatus - Culicidae - winter biology - survival - developmental duration developmental threshold

Members of the Culex pipiens L. group are worldwide distributed, and important vectors of pathogenous of human and animal diseases. The taxonomic status of each form belonging to the group is still subject to controversy, being considered as species for some authors and subspecies for others. Brewer et al. $(1987,1991)$ reported both $C x$. pipiens pipiens and $C x$. pipiens quinquefasciatus and hybrids between them in Córdoba Province, and Almirón et al. (1995) obtained fertile hybrids in laboratory, so in this paper they will be consider as subspecies.

The winter biology of the $C x$. pipiens group has been quite well studied in the Northern Hemisphere. Geographic distribution of the group, immature stage development, dynamics of adult populations, and the physiology of hibernation have been considered (Farid 1949, Barr 1957, McMillan 1958, Tekle 1960, Forattini 1965). In South America, Rachou (1957) and Scorza (1972) studied different biological aspects of $C x$. pipiens fatigans Wied. (=quinquefasciatus).

In cool, temperate areas $C x$. pipiens pipiens

\footnotetext{
This work was supported in part by CONICOR (Consejo de Investigaciones Científicas y Tecnológicas de Córdoba).

${ }^{+}$Researcher of Consejo Nacional de Investigaciones Científicas y Técnicas de la República Argentina (CONICET). Fax 54-51-244092

Received 18 January 1996

Accepted 20 May 1996
}

hibernates as nulliparous, inseminated females that enter facultative reproductive diapause. The male does not enter diapause and does not survive the winter (Mitchell 1983, Bowen et al. 1988). Although diapausing $C x$. pipiens does not display host-seeking behavior, some females can be induced to take a blood meal if they are placed in contact with or in proximity to a host for a prolonged period in a small cage (Eldridge 1968). However, diapausing $C x$. pipiens can not use a blood meal to synthesize lipids; diapausing females with limited lipid reserves are unable to obtain sufficient energy from a single blood meal to survive extended hibernation (Mitchell \& Briegel 1989a). In nature, overwintering females do not take blood or develop eggs, a phenomenon called "gonotrophic concordance" and considered to be the mark of true hibernation (Mitchell \& Briegel 1989b).

On the other hand, Cx. pipiens quinquefasciatus does not overwinter in a state of facultative reproductive diapause like $C x$. pipiens pipiens. Hayes (1975) and Hayes and Hsi (1975) reported yearround egg production for an isolated quinquefasciatus population in Houston, Texas, during a 2.5 -year period. The continous reproduction occurred despite cold and snowfall. Scorza (1972) suggested that $C x$. pipiens fatigans from Venezuela would be a homodynamics species with variations of its populational size according to precipitations. In Brazil, Rachou (1957) was able to find $C x$. pipiens fatigans throughout the year for studies on Wuchereria bancrofti. 
Information about geographical distribution of the members of the $C x$. pipiens group in Argentina, indicates that quinquefasciatus occurs from the provinces of Buenos Aires and Mendoza northwards, whereas pipiens is found from Buenos Aires southwards to the Santa Cruz Province (Duret 1953, Mitchell et al. 1984, Mitchell \& Darsie 1985). Brewer et al. (1987) reported the presence of intermediate forms in Córdoba Province, and Almirón et al. (1995) extended that area to the south of Santa Fe Province. Mitchell (1988) and Mogi (1992) correlated the distribution of quinquefasciatus and the $10^{\circ} \mathrm{C}$ isotherm in the coldest month in the Southern Hemisphere, although that correlation is an extrapolation, at least in South America, not based on experimental evidence.

There is little information about winter biology of mosquito species in Argentina. Adults of quinquefasciatus were collected throughout the year in Buenos Aires Province (Prosen et al. 1960). These authors found a few individuals during the winter. No more details are given about the winter biology of this culicid. In Córdoba Province with continental temperate climate, immature stages and adults of quinquefasciatus were collected during the cold months (Almirón \& Brewer 1994, 1995).

In this contribution on the quinquefasciatus winter biology in South America, the aim was to determine survival, developmental duration, and developmental threshold.

\section{MATERIALS AND METHODS}

Mass rearing in the laboratory to obtain adults - Egg rafts collected in the outskirts of Córdoba city were reared individually in plastic trays $(1000$ $\mathrm{ml}$ ) with water from the breeding place or tap water. Larvae were fed on a mixture of dog and rabbit balanced food and powder yeast and liver $(0.001$ $\mathrm{g} / \mathrm{ml}$ ). Pupae were sexed to avoid mating until cohorts were organized in the field. Adults were fed with 10\% sugar solution. The offspring of each raft was identified based on the male genitalia (Sundararaman 1949) of five individuals. Cages and trays were kept at a $25 \pm 3^{\circ} \mathrm{C}, 50-70 \%$ R.H. and photoperiod of $16 \mathrm{hr}$ length. The adults obtained were taken to the field where cohorts were arranged to study survival and oviposition under natural conditions of temperature, relative humidity and photoperiod.

Adult cohorts kept in the field - Cohorts with males and females (1-7 day-old) were kept in cages $(0.3 \times 0.3 \times 0.3 \mathrm{~m})$ placed in a farm gallery (Córdoba city) during autumn-winter (March-September) of 1987-89. They were studied under three experimental conditions: five unfed cohorts (A), five cohorts fed with sugar solution (B) and seven cohorts fed with sugar solution and blood (C). The number of individuals per cohort was between 4050 of each sex, except for one unfed cohort (A) that was arranged with 25 males. The cages of cohorts $\mathrm{B}$ and $\mathrm{C}$, were weekly provided with sugar solution. For the cohorts $\mathrm{C}$, a host chicken was offered fortnightly starting the first week the cohorts were placed in the field. Two cohorts A, B and C, were established in June of 1987 and 1988 respectively. In 1989, one of each cohorts were arrenged in May, plus other cohort $\mathrm{C}$ in June, and one cohort A, B and two cohorts C in July. Each cohort was checked until all individuals had died. The number and sex of dead mosquitoes, and for cohorts $\mathrm{C}$, the number of engorged females, and the number of rafts laid were recorded. The rearing conditions were respectively: minimum temperature average of $8.92^{\circ} \mathrm{C}$ and maximum temperature average of $18.7^{\circ} \mathrm{C}$ (range $-3^{\circ}-34^{\circ} \mathrm{C}$ ), photoperiod of $11.02 \mathrm{hr}$ light (range $10.9-11.3 \mathrm{hr}$ ) for cohorts $\mathrm{A} ; 8.72^{\circ} \mathrm{C}$ and $18.42^{\circ} \mathrm{C}\left(-3^{\circ}-34^{\circ} \mathrm{C}\right), 11.6$ hr light $(10.9-13.6)$ for cohorts $\mathrm{B} ; 8.65^{\circ} \mathrm{C}$ and $18.43^{\circ} \mathrm{C}\left(-3^{\circ}-34^{\circ} \mathrm{C}\right), 11.66 \mathrm{hr}$ light $(10.9-13.6 \mathrm{hr})$ for cohorts $\mathrm{C}$. Photoperiod data were provided by the National Meteorological Service. It was not possible to record the relative humidity. ANOVA was used to analyze adult mean lifetime.

Immature stage cohorts kept in the field - Egg rafts obtained from cohorts $\mathrm{C}$ were kept in the same gallery as to adult cohorts and reared according to the methodology described above. Each egg raft (cohort in the future) was checked every week until all adults had emerged. After hatching, rafts were taken to the laboratory to count the number of viable and non-viable eggs. Pre-adult developmental duration, survival and sex ratio were calculated. The rearing conditions were respectively: in 1987, min. temperature average of $8.96^{\circ} \mathrm{C}$ and max. average of $21.12^{\circ} \mathrm{C}$ (range $0^{\circ}-34^{\circ} \mathrm{C}$ ), photoperiod of $12.3 \mathrm{hr}$ light (range $11.1-13.6 \mathrm{hr}$ ); in 1988, $10.12^{\circ} \mathrm{C}$ and $21.28^{\circ} \mathrm{C}\left(3^{\circ}-36^{\circ} \mathrm{C}\right), 13.5 \mathrm{hr}$ light $(12.7$ - $13.6 \mathrm{hr})$; in $1989,11.03^{\circ} \mathrm{C}$ and $20.56^{\circ} \mathrm{C}\left(-3^{\circ}\right.$ $\left.31^{\circ} \mathrm{C}\right), 12.4 \mathrm{hr}$ light $(10.9-14.5 \mathrm{hr})$.

Egg, larva and pupa mean developmental duration obtained during the three years were analyzed by means of ANOVA. The t-test was also used to detect differences among the sex ratios obtained, turning, previously, the proportions into arc-sen.

Developmental threshold - The principal extrinsic factors that affect rates of growth and development are temperature, nutrition and larval density among others. Developmental velocity is defined as the reciprocal of the developmental duration, and is positively correlated with temperature. The curve relating developmental velocity with temperature is sigmoid, but over its central region it is effectively linear. Extrapolation from 
the linear region of the curve to the temperature axis indicates a theoretical developmental zero (Begon et al. 1990, Clements 1992, Mogi 1992).

Developmental velocity was estimated for each cohort of immature stages kept in the field. Developmental velocity was also estimated for five cohorts kept at $25+3^{\circ} \mathrm{C}$, and photoperiod of $16 \mathrm{hr}$ light in the laboratory. Relationship of developmental velocity to mean temperature recorded during the study period of each cohort was calculated following the linear regression model (Clements 1992, Mogi 1992).

\section{RESULTS}

Adult cohorts kept in the field - Unfed males and females lived until the second and third weeks respectively (Cohorts A); 68-100\% of mortality was recorded during the first week, being more notable for males. Males and females fed with sugar solution survived until the fifth and sixth weeks respectively (Cohorts B). In cohorts C (fed with sugar solution and blood) males lived up to six weeks while females survived until the fourteenth. Females laid eggs after blood intake even during the cold seasons. Eleven rafts were recorded (from July to September) in 1987, 1 (September) in 1988 and 27 (from June to September) in 1989, so there was gonotrophic concordance. There were no significant differences among the results obtained neither between males $(\mathrm{F}=1.159 ; \mathrm{n}=17 ; \mathrm{P}=0.362)$ nor between females $(\mathrm{F}=1.28 ; \mathrm{n}=17 ; \mathrm{P}=0.329)$ for none of the three treatments. Male and female mean lifetime is shown in Table I. Only female longevity showed a significant difference $(\mathrm{F}=9.758 ; \mathrm{n}=17$; $\mathrm{P}=0.007$ ) among the three treatments (Table I). According to the results obtained, female survival is seemingly more related to food availability than to environment temperature variations.
Males that were fed lived longer than those remaining unfed (Fig. 1) though there were no differences among the results obtained according to ANOVA. Similar results were obtained for females (Fig. 1), but in this case there were differences among the treatments.

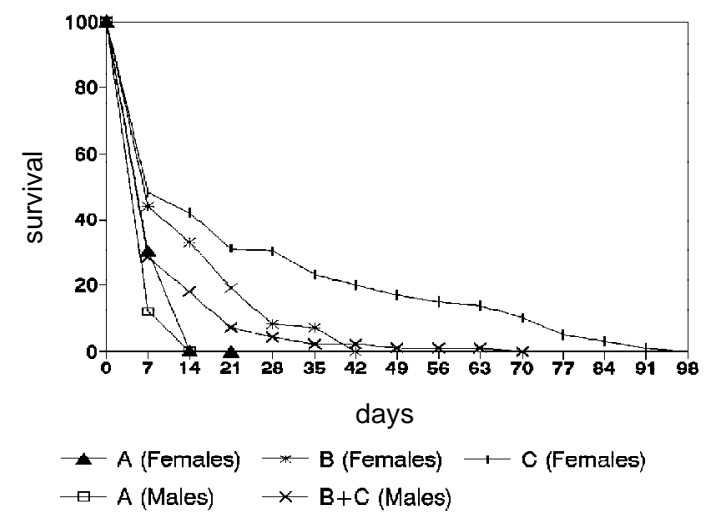

Fig. 1: male and female survival of Culex pipiens quinquefasciatus in cohorts unfed (A), fed with sugar solution (B) and fed with sugar solution and blood (C) during the three years of study.

Immature stage cohorts kept in the field - Five cohorts - rafts - (357 eggs; $\overline{\mathrm{X}}$-mean- $=71.4$ eggs/ raft, $\mathrm{S}$-standard deviation- $=21.68)$ were studied in 1987, 1 raft (66 eggs) in 1988 and 25 rafts (3196 eggs; $\bar{X}=127.84, S=26.97$ ) in 1989 . The mean number of eggs per raft obtained during the first two years was notably lower than that recorded in 1989. There were significant differences (t-test, $p$ $<0.05$ ) between values obtained in 1987 and 1989 .

TABLE I

Mean lifetime (in days) of Culex pipiens quinquefasciatus adults kept in field during three autumn-winter periods

\begin{tabular}{cllccccccc}
\hline \multirow{2}{*}{ Cohorts } & Replicates & \multicolumn{2}{c}{1987} & \multicolumn{2}{c}{1988} & \multicolumn{2}{c}{1989} & \multicolumn{2}{c}{ Mean lifetime } \\
& & Male & Female & Male & Female & Male & Female & Male & Female \\
\hline \multirow{2}{*}{ A } & 1 & 0 & 0.45 & 0.43 & 0.72 & 0 & 0.17 & $0.27( \pm 0.30)$ & $0.73( \pm 0.44)$ \\
& 2 & 0.20 & 1.03 & & & 0.72 & 1.29 & & \\
B & 1 & 0 & 0 & 5.88 & 11.12 & 0 & 2.18 & $2.84( \pm 3.18)$ & $6.06( \pm 5.50)$ \\
& 2 & 6.57 & 12.50 & & & 1.75 & 4.52 & & \\
C & 1 & 0 & 27.79 & 10.19 & 13.98 & 0.13 & 6.78 & $5.22( \pm 7.35)$ & $18.09( \pm 10.77)$ \\
& 2 & 19.92 & 31.07 & & & 1.26 & 12.52 & & \\
& 3 & & & & & 1.90 & 5.91 & & \\
& 4 & & & & & 3.16 & 28.58 & & \\
\hline
\end{tabular}

The number of individuals by cohort was 40-50 of each sex, excepted for one cohort A with 25 males; A: 5 cohorts unfed; B: 5 cohorts fed with sugar solution; C: 7 cohorts fed with sugar solution and blood; standard deviation in parenthesis. 
As only one raft was recorded in 1988, it was not possible to include it in the data analysis. Nevertheless, its size was lower than the mean value obtained in 1989. Mean development time from egg to adult was between 43-62 days (Table II). There were no differences among the results obtained during the three years $(\mathrm{F}=1.206 ; \mathrm{n}=29 ; \mathrm{P}=$ $0.2819)$. Relative mortality was higher in the egg and larval stages than in the pupal stage (Table II). Between 10-40\% of hatched eggs reached the adult stage. The sex ratio was practically $1: 1$ in 1987 and 1989. The t-test $(p>0.05)$ did not show significant differences between the results. However, values recorded in 1988 indicate that the male to female ratio was $2: 1$.

Developmental threshold - Developmental duration from egg to adult for the five cohorts reared in the laboratory was between 12.66-18.26 days $(\bar{X}=15.26, S=1.99)$. Values obtained under warm conditions were lower than those obtained in the field (43-62 days). Fig. 2 shows the relation between immature stage developmental velocity and temperature under field and laboratory conditions. Regression was significant $\left(\mathrm{R}^{2}=0.82 ; \mathrm{n}=30 ; \mathrm{P}<\right.$ $0.000001)$, i.e., low temperature increased the period required for egg-to-adult development. The developmental threshold temperature was estimated as $9.52^{\circ} \mathrm{C}$ according to regression equation $y=-0.0377+0.00396 t$ (Fig. 2)

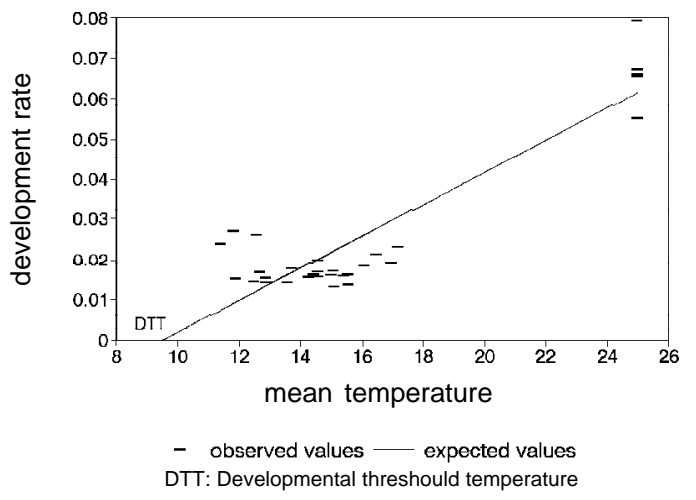

Fig. 2: linear regression relating developmental velocity of Culex pipiens quinquefasciatus immature stages to the rearing temperature in the field and laboratory.

\section{DISCUSSION}

As expected adults of $C x$. pipiens quinquefasciatus lived only a few days without food during autumn-winter. Their life period was longer when they fed on sugar solution and even more so when females intook blood. After intaking blood females laid eggs even during the cold seasons. Despite the low temperatures eggs hatched, larvae pupated and adults emerged, that is, immature stages continued their development throughout the cold months but to a slower speed than they did under warmer conditions.

TABLE II

Mean developmental duration (in days) and survival of immature stages and sex ratio of Culex pipiens quinquefasciatus

\begin{tabular}{lrrr}
\hline & 1987 & 1988 & 1989 \\
\hline Mean developmental duration & $6.25( \pm 0.50)$ & 5.00 & $7.51 \quad( \pm 0.86)$ \\
$\quad$ Egg & $50.09( \pm 11.13)$ & 29.70 & $44.25( \pm 11.00)$ \\
Larva & $6.26( \pm 0.09)$ & 8.66 & $6.90( \pm 0.41)$ \\
Pupa & $62.60( \pm 10.74)$ & 43.36 & $58.67 \quad( \pm 9.91)$ \\
$\quad$ Egg-Adult & & & \\
Survival & $73.78( \pm 24.01)$ & 56.06 & $82.64( \pm 12.27)$ \\
$\quad$ Egg (\% of hatching) & $34.29( \pm 25.50)$ & 40.90 & $10.83( \pm 8.07)$ \\
$\quad 29.68( \pm 21.89)$ & 40.90 & $9.10( \pm 8.96)$ \\
$\quad$ Pupa (\% of emergennce) & $32.54( \pm 24.71)$ & 74.35 & $20.08( \pm 15.24)$ \\
Relative mortality: egg & $58.75( \pm 20.00)$ & 25.64 & $77.96( \pm 14.03)$ \\
Relative mortality: larva & $8.69( \pm 9.49)$ & 0.00 & $1.93( \pm 1.67)$ \\
Relative mortality: pupa & $69.74( \pm 21.31)$ & 59.09 & $89.71 \quad( \pm 8.07)$ \\
Total pre-adult mortality & & &
\end{tabular}

1987: $\mathrm{N}=5$ rafts; 1988: $\mathrm{N}=1 \mathrm{raft}$; 1989: $\mathrm{N}=25$ rafts; standard deviation in parenthesis 
Unfed quinquefasciatus females kept at $5^{\circ} \mathrm{C}$ only survived for two weeks (Tekle 1960), whereas females fed with $15 \%$ sugar solution during two weeks lived for 47-51 days. Therefore, survival during autumn-winter would be greater when mosquitoes may feed. According to our results females fed with sugar solution could survive until the sixth week and those that intook blood could reach the fourteenth week, but not long enough to overwinter.

Force-fed diapausing pipiens females do not use the blood for lipogenesis and only some of them use the blood to initiate vitellogenesis (Mitchell \& Briegel 1989b). In contrast, quinquefasciatus cannot enter diapause and survives the winter by continued host-seeking and reproductive activity (Tekle 1960); because of its inability to hibernate quinquefasciatus occurs in warm and temperate regions.

Ikeshoji (1966) and Scorza (1972) concluded that the body size, the quality and quantity of blood taken by quinquefasciatus females, the number of gonotrophic cyles as well as the chronological age affected the egg production. No conclusion is given because none of those variables were recorded in this study.

Our results about pre-adult mortality agree with those reported by Hayes and Hsi (1975) and Gomez et al. (1977), though our values are higher than those recorded by the latter authors. Perhaps this phenomenon is closely related to the low rearing temperatures.

Differences between the male to female proportion was recorded in one of our three years of study. Roubaud (1932) recorded an extra production of males that he called spanoginy. Reer (1901) pointed out that quinquefasciatus produces a higher quantity of males to females. Although for Tate and Vincent (1936) the spanoginy is due to the lack of blood intake, this could not be the reason in our experiments since they were allowed to take blood.

Immature stages of quinquefasciatus reared at $15^{\circ}$ and $10^{\circ} \mathrm{C}$ required 41 and 60 days respectively to complete their development (Tekle 1960). The developmental duration, during the winter, from egg to adult for eggs laid in January reported by Hayes and Hsi (1975) was 48 days. In Córdoba city the mean temperature from May to September (autumn-winter) is between $10^{\circ}-15^{\circ} \mathrm{C}$. The pre-adult mean developmental duration we obtained in the field agrees with the observations of Tekle (1960) and Hayes and Hsi (1975). The time required by quinquefasciatus from egg hatching to adult under $20^{\circ}-23^{\circ} \mathrm{C}$ was about 8 days according to Shelton (1973). At $26 \pm 2^{\circ} \mathrm{C}$, Gomez et al. (1977) reared immature stages whose developmental duration was 10.57 days for females and 10.29 for males. There are no notable differences among the results obtained for the individuals kept under colder or warmer conditions.
Our developmental threshold temperature $\left(9.52^{\circ} \mathrm{C}\right)$ estimated agree with the $10.1^{\circ} \mathrm{C}$ reported by Mogi (1992) for quinquefasciatus New Zealand strain and those he calculated for Philippines $\left(9.5^{\circ}\right.$ $\left.10.4^{\circ} \mathrm{C}\right)$, Japan $\left(9.6^{\circ} \mathrm{C}\right)$ and Texas $\left(9.9^{\circ} \mathrm{C}\right)$. The developmental threshold estimated indicates that our zone of study is practically at the threshold limit, supporting the "somewhat arbitrary selected averaged cold-month isotherms of $10^{\circ} \mathrm{C}$ as the lower limits for continuous mosquito breeding activity and development during the respective winters of the northern and southern hemisphere" (Mitchell 1988). Thus in our country, quinquefasciatus would not occur where winter temperatures are lower than $9.52^{\circ} \mathrm{C}$, at least during the cold period. Ross (1947) noted that quinquefasciatus was abundant in southern Illinois during July and August, and usually disappeared soon after the first cool weather in September. Rosay and Nielsen (1974) observed that quinquefasciatus was uncommon in Salt Lake City, Utah, during the summer months and speculated that the species reinvades the northern parts of its range each year. According to Mitchell et al. (1980) this is perhaps typical of its pattern of seasonal abundance toward the northern limits of its range; since this species cannot overwinter, it may not persist in such areas during the winter.

According to the development time from egg to adult we obtained throughout the cold seasons, adults emerge during winter from eggs laid at the begining of autumn. Our results showed that females survived at most six weeks when they were fed only on sugar solution so they would also die during winter. If they fed on blood they could survive longer but not enough to pass the winter. Under our experimental conditions and considering the longest immature stage mean developmental duration (62 days) and the longest female mean lifetime (18 days), two generations of quinquefasciatus occured during the autumn-winter period in Córdoba. Although the obtained survival rate showed that only $10-40 \%$ of hatched eggs reached the adult stage, apparently this amount of individuals would be enough to maintain the population. Reeves (1965) pointed out that a mosquito population can be maintained if only a few females succeed in ovipositing.

\section{ACKNOWLEDGMENTS}

To Dr D Gorla for his suggestions. To Dr M Sabattini and Dr C Mitchell for their comments on the manuscript.

\section{REFERENCES}

Almirón WR, Brewer ME 1994. Immature stages of mosquitoes (Diptera: Culicidae) collected during the autumn-winter period in Córdoba Province, Argentina. Mem Inst Oswaldo Cruz 89: 625-628.

Almirón WR, Brewer ME 1995. Distribución estacional de Culicidae (Diptera) en áreas periféricas de Córdoba (Argentina). Ecol Austral 5: 81-86. 
Almirón WR, Humeres SG, Gardenal CN 1995. Distribution and hybridization between Culex pipiens and Culex quinquefasciatus (Diptera: Culicidae) in Argentina. Mem Inst Oswaldo Cruz 90: 469-473.

Barr AR 1957. The distribution of Culex pipiens pipiens and Culex pipiens quinquefasciatus in North America. Am J Trop Med Hyg 6: 153-165.

Begon M, Harper JL, Townsend CR 1990. Ecology. Individuals, Populations and Communities. Blackwell Scientific Publications, 945 pp.

Bowen MF, Davis EE, Haggart DA 1988. A behavioral and sensory analysis of host seeking behavior in the diapausing mosquito Culex pipiens. J Insect Physiol 34: 805-813.

Brewer M, Almirón W, Bianchini N, Buffa L 1991. Fauna de Culicidae (Diptera) de Córdoba, República Argentina. Bol Acad Nac Cienc (Córdoba) 59: 241-249.

Brewer M, Buffa L, Almirón W 1987. Culex pipiens quinquefasciatus Say, 1823 y Culex pipiens pipiens L., 1758 (Dipt.: Culicidae) en Córdoba, Argentina. Rev per Ent 29: 69-72.

Clements AN 1992. The biology of mosquitoes. I. Development, nutrition and reproduction. Chapman \& Hall, London, 509 pp.

Duret JP 1953. Notas sobre Culex argentinos (Diptera: Culicidae). Rev San Milit Argent 52: 272-278.

Eldridge BF 1968. The effect of temperature and photoperiod on blood-feeding and ovarian development in mosquitoes of the Culex pipiens complex. Am J Trop Med Hyg 17: 133-140.

Farid MA 1949. Relationships between certain populations of Culex pipiens Linnaeus and Culex quinquefasciatus Say in the United States. Am J Hyg 49: 83-100.

Forattini OP 1965. Entomología Médica. Vol. II. Culicini: Culex, Aedes, Psorophora. Universidade de São Paulo, 506 pp.

Gómez C, Rabinovich JE, Machado-Allison CE 1977. Population analysis of Culex pipiens fatigans Wied. (Diptera: Culicidae) under laboratory conditions. $J$ Med Ent 13: 453-463.

Hayes J 1975. Seasonal changes in population structure of Culex pipiens quinquefasciatus Say (Diptera: Culicidae): study of an isolated population. $\mathrm{J} \mathrm{Med}$ Entomol 12: 167-178.

Hayes J, Hsi BP 1975. Interrelationships between selected meteorologic phenomena and immature stages of Culex pipiens quinquefasciatus Say: study of an isolated population. J Med Entomol 12: 299-308.

Ikeshoji T 1966. Studies on mosquito attractans and stimulants. Part I. Chemical factors determinig the choice of oviposition site by Culex pipiens fatigans and pallens. Japan J Exp Med 36: 49-59.

McMillan ML 1958. Study of a naturally occurring population intermediate between Culex pipiens pipiens and Culex pipiens quinquefasciatus. Am J Trop Med Hyg 7: 505-511.

Mitchell CJ 1983. Differentiation of host seeking behavior from blood-feeding behavior in overwintering Culex pipiens (Diptera: Culicidae) and observations on gonotrophic dissociation. J Med Entomol 20: $157-163$.

Mitchell CJ 1988. Occurrence, biology, and physiology of diapause in overwintering mosquitoes. p, 191217. In TP Monath. The arboviruses: Epidemiology and ecology. Vol. I. CRC Press, Inc., Boca Raton, Florida.

Mitchell CJ, Darsie RF, Jr 1985. Mosquitoes of Argentina. Part II. Geographic distribution and bibliography (Diptera: Culicidae). Mosq Syst 17: 279-360.

Mitchell JC, Briegel H 1989a. Inability of diapausing Culex pipiens (Diptera: Culicidae) to use blood for producing lipids reserves for overwinter survival. $J$ Med Entomol 26: 318-326.

Mitchell JC, Briegel H 1989b. Fate of blood-meal in force-fed, diapausing Culex pipiens (Diptera: Culicidae). J Med Entomol 26: 332-431.

Mitchell JC, Francy DB, Monath TP 1980. Arthropod vectors, p. 313-379. In TP Monath, St. Louis Encephalitis. American Public Health Association, Washington, DC.

Mitchell CJ, Darsie RF, Jr, Monath TP 1984. Occurrence of autogenous Culex pipiens Linnaeus 1758 (Diptera: Culicidae) in Argentina and notes on distribution of the complex. Mosq Syst 16: 308-316.

Mogi M 1992. Temperature and photoperiod effects on larval ovarian development of New Zealand strains of Culex quinquefasciatus (Diptera: Culicidae). Ann Entomol Soc Am 85: 58-66.

Prosen AF, Martinez A, Carcavallo RV 1960. La familia Culicidae (Diptera) de la rivera fluvial de la provincia de Buenos Aires. An Inst Med Reg 5: 101-113.

Rachou RG 1957. Distribução geográfica das filarioses humanas no Brasil. Rev Bras Malar Doen Trop 9: 79.

Reer DC 1901. Malaria: its parasitology with a description of method demostrating the organism in man and animals. Practitioner 13: 271.

Reeves WC 1965. Ecology of mosquitoes in relation to arboviruses. Annu Rev Entomol 10: 25-46.

Rosay B, Nielsen LT 1974. The Culex pipiens in Utah. Proc 26th Ann Meet Utah Mosq Abatement Assoc.p. 28-31.

Ross HH 1947. The mosquitoes of Illinois. III. Nat Hist Sur Bull 24: 1-96.

Roubaud E 1932. Recherches sur les variations trophiques et biologiques des peuplementes de l'Anopheles maculipennis. Bull Soc Path Exot 25: 755-761.

Scorza JV 1972. Observaciones bionómicas sobre Culex pipiens fatigans Wied., 1829 de Venezuela. Universidad de los Andes, Mérida, 198 pp.

Shelton RH 1973. The effect of temperatures on development of eight mosquito species. J Am Mosq Control Assoc 33: 1-12.

Sundararaman S 1949. Biometrical studies on intergradation in the genitalia of certain populations of Culex pipiens and Culex quinquefasciatus in the United States. Am J Hyg 50: 307-314.

Tate P, Vincent M 1936. The biology of autogenous and anautogenous races of Culex pipiens L. (Diptera: Culicidae). Parasitol 28: 115-145.

Tekle A 1960. The physiology of hibernation and its role in the geographical distribution of populations of the Culex pipiens complex. Am J Trop Med Hyg 9: 321-330. 